\title{
Perceptions of Prominent Neighborhood Individuals Regarding Neighborhood Factors and Intimate Partner Violence
}

\author{
Michael Yonas, Aletha Y. Akers, Jessica G. Burke, Judy C. \\ Chang, Aletha L. Thomas, and Patricia O'Campo
}

\begin{abstract}
Research addressing the impact of neighborhood factors on intimate partner violence (IPV) often lacks discussion of how and why such factors impact IPV. In order to address this gap, 16 prominent neighborhood individuals (PNI) from 4 lowincome urban neighborhoods were asked to share through in-depth interviews their insights and perceptions of IPV as an issue in their neighborhoods, and the relationship between social and structural neighborhood-level factors and IPV. PNIs most often associated IPV with only physical violence. Several did not feel IPV was a significant issue in their neighborhood, confirming a lack of awareness and underreporting of IPV. However, other PNIs were able to speak of the relationship between IPV and neighborhood factors, including lack of opportunities for employment, vacant housing, trash management, lack of community awareness, and social capacity to act to address IPV. Results provide unique insights regarding the mechanisms linking neighborhood factors to IPV outcomes. These results contribute to a deeper understanding of contextual influences upon IPV, the development of tailored quantitative research and to the design of local multi-level public health IPV intervention and prevention efforts.
\end{abstract}

KEYWORDS Intimate partner violence, Neighborhood factors, Community perceptions

\section{INTRODUCTION}

Intimate partner violence (IPV) is a significant public health problem that demands intervention. IPV is defined as actual or threatened violence that is physical, sexual, or emotional in nature and is perpetrated by a current or former spouse or nonmarital dating partner of the same or opposite sex. ${ }^{1,2}$ Victims of IPV are present among all geographic settings, ethnic groups, age ranges, socioeconomic levels and both genders. Each year in the United States, women experience about 4.8 million intimate partner-related physical assaults and rapes. In 2005, 1,510 deaths were reported due to IPV; $78 \%$ of these victims were female and $22 \%$ were male. ${ }^{3,4}$

While a considerable body of literature has explored individual and relationship factors associated with IPV, less is known about the relationships between neighborhood environment and experiences of IPV. Starting in the late 1990s, researchers such as Heise ${ }^{5}$ and Dutton ${ }^{6}$ began advocating for the adoption of an integrated, ecological approach for a more complete understanding of the multiple

\footnotetext{
Yonas, Akers, Burke, Chang, Thomas, and O’Campo are with the University of Pittsburgh, Pittsburgh, PA, USA.

Correspondence: Michael Yonas, University of Pittsburgh, Pittsburgh, PA, USA. (E-mail: may24@pitt.edu)
} 
levels of factors influencing women's experiences of abuse. ${ }^{5-7}$ Such an ecological approach acknowledges the multiple levels influencing factors impacting a health problem, and is a useful tool for guiding intervention development. Neighborhood context is one level of the ecological model for addressing IPV that requires more attention.

Recent years have witnessed a growing interest in multi-level research examining the role of macro-level neighborhood effects on women's experiences of IPV. $^{7-10}$ O'Campo et al.'s ${ }^{7}$ early study of IPV perpetrated during the childbearing year found that multiple neighborhood level variables related to socioeconomic position (e.g., per capita income, unemployment rate, and ratio of home owners to renters) were related to risk of violence. ${ }^{7}$ In addition, when the neighborhood-level variables were added to the model, the relationships between the individual-level variables and the outcome were altered, highlighting the roles of poverty, residential stability, mobility, and male unemployment. More recent quantitative work by Li et al. ${ }^{11}$ lends additional support to the assertion that neighborhood contextual factors (e.g., residential instability) are associated with increased risk of IPV. ${ }^{7,9-11}$

While existing quantitative research supports a relationship between neighborhood context and IPV, results have contributed little to our understanding of how neighborhood factors are related to IPV. Qualitative work by Burke et al. ${ }^{12}$ and O'Campo et al. ${ }^{13}$ provides insights into the relationships between urban neighborhood environment and IPV by using a participatory data collection process to examine perceptions and mechanisms associated with neighborhood factors related to IPV. For example, participants felt that a variety of neighborhood characteristics, including physical factors (e.g., trash), economic factors (e.g., poverty), resident factors (e.g., people not caring), and community resources (e.g., community centers), were related to women's experiences of IPV. Additional later work by Burke et al. ${ }^{10}$ found that connectedness between neighborhood residents and positive community resources were perceived to be important factors affecting IPV cessation.

A wealth of evidence supports the role of collective efficacy, defined as shared trust and willingness of neighborhood residents to engage in social control in preventing neighborhood violence. ${ }^{14,15}$ However, little is known about how such examples of social interactions foster the conditions for increased awareness and action to address IPV. ${ }^{16,17}$ A longitudinal study of urban women found that neighborhood context was significant to cessation of IPV, particularly within neighborhoods where residents felt that fights between families and friends is not a private matter. ${ }^{17}$ Attaining and examining the perspective of community "experts" involved in neighborhood violence prevention activities is essential to understand the neighborhood social and structural dynamics impacting IPV. ${ }^{17,18}$

The primary goal of the research presented was to explore the perceptions of formal and informal community leaders from 4 urban neighborhoods regarding the relationship between neighborhood factors and IPV. We specifically examined the following issues; (a) identification of IPV as a priority neighborhood issue of concern, (b) perceptions of neighborhood factors related to IPV, and (c) thought regarding neighborhood resources and social capacity to intervene to address IPV.

\section{METHODS}

Funding was obtained from the Centers for Disease Control and Prevention for the "Community Pathways to Violence" (CDC R49/CCR318515) research project 
which examined the relationship between neighborhood context and violence in urban Baltimore City, MD, United States. Qualitative interviews were conducted with prominent neighborhood individuals (PNIs) to explore their perceptions regarding 2 types of violence: youth violence and IPV. The results presented here address the findings related to IPV. Greater detail associated with this study, neighborhood selection process and procedures and the findings specific to youth violence can be found elsewhere ${ }^{18,19}$. The study was approved by the Johns Hopkins Bloomberg School of Public Health Institutional Review Board.

\section{Neighborhood Selection}

We operationalized neighborhood designations through the use of census block groups. Census block groups are generally small in size, usually containing between 600 and 3,000 individuals, and are relatively confined to a "walkable" areas of approximately 4 to 8 city blocks. ${ }^{20}$ Census block group have been found to be an appropriate proxy for identifying immediate influences on the lives and experiences of local individuals. ${ }^{21}$ Details of the neighborhood selection process can be found elsewhere. ${ }^{18}$ In brief, we selected all neighborhoods falling within the lowest quartile of wealth in Baltimore City and then used a used a combination of demographic, economic, and violence-related data to sort neighborhoods based on their overall high or low risk for neighborhood violence occurrence. Using city planning data, we determined that our high- and low-risk study neighborhoods were otherwise very similar. A majority of the households $(70 \%)$ had median household incomes below $\$ 25,000$ per year. Few of the households $(13 \%)$ in the neighborhood were owneroccupied and close to one third of the all the houses in the study neighborhoods were vacant. $^{22}$

\section{Participant Selection}

We actively sought out formal and informal community leaders who were involved in, or perceived as being involved in, efforts to address issues related to violence. While there have been a variety of different approaches identified and strategies utilized for determining community opinion leaders, we sought neighborhood experts whom we referred to as PNIs. ${ }^{23}$ The descriptive term of "prominent neighborhood individual" was selected with the help of study participants. While the majority of participants could be referred to as more formal community leaders (e.g., residents, pastors, and program coordinators), there were a few participants who were involved in illicit drug sales, perceived by others (i.e., their neighbors) as informal leaders influencing efforts to address violence. These individuals were not comfortable with being described as community leaders but acknowledged their complex role in the neighborhood. During neighborhood walkthroughs, contact was made with more than 60 adults. The process of selecting PNIs was consensus driven, as neighborhood residents were asked to identify individuals who were involved in local efforts to address and prevent neighborhood violence. Individuals were identified and designated as a PNI once 3 to 5 neighbor references were obtained identifying the individual as a prominent neighborhood figure.

A total of 16 prominent neighborhood individuals were invited, and agreed, to participate. A majority of these local "experts" were either current $(N=9)$ or past residents $(N=4)$, and those who were past residents had come back to work in the study neighborhoods. All of the participants were actively involved in the study neighborhoods. The 3 individuals who were not residents coordinated local 
programs serving youth and families or pastors of churches. Ten of the prominent neighborhood individuals were men and 6 were women and they ranged in age from 32 to 77 years old, with an average age of 49 . Neighborhood walkthroughs, initial contact and in-depth interviews were conducted over a 16 -week period of time (April to July 2003).

\section{In-depth Qualitative Interview Process}

The 60-90 min qualitative interviews were conducted in locations most convenient for the participants, and ranged from individuals' private homes to offices to exterior house stoops. The study objectives were reviewed and each PNI signed a written informed consent. Participants were reimbursed $\$ 20$ for their time and expertise.

An interview guide composed of semi-structured, open-ended questions was used to facilitate the interviews. Consistent with the larger study aims, the interview questions included those specific to neighborhood factors perceived as related to IPV and youth violence. The ordering of the field guide violence topic questions was varied so that every other participant was first asked about youth violence and then IPV and vice versa; the remaining participants were first asked about IPV and then youth violence.

The questions specific to the research presented here provided an opportunity to explore participants' definitions of IPV, perspectives on community social norms regarding IPV, beliefs regarding IPV prevalence and their community's capacity for and actual responses to these situations. Example field guide questions included, "Is IPV an important issue to people living in your neighborhood?", "How do you feel that people living in the neighborhood respond to IPV?"

\section{Qualitative Data Analysis}

The audio-taped interviews were transcribed verbatim. All PNIs were provided a copy of their transcribed interview to review for accuracy, to make corrections or to further illustrate concepts explored during the interview. All PNIs reviewed their transcripts and no changes or edits were requested by study participants. Qualitative software data management package NVivo 6.0 was used for indexing, exploring, and analyzing the qualitative interview information. ${ }^{24}$ The NVivo program allowed the researchers to develop and use codes, to extract and analyze related data categories and themes arising from the PNI interviews. For example, all text segments that addressed "neighborhood resources" in relation to IPV were identified using a code called "neighborhood factor community resources." Two of the project investigators (MY, JB) analyzed the transcripts.

Members of the research team read through a random sample of 3 of the transcribed interviews and independently developed the initial codes from themes arising from the responses given by PNIs in the interviews. When compared, the independently developed coding structures of each researcher were highly consistent. Therefore, their coding structures were merged and used to create a final thematic codebook. This codebook was used to code and analyze the remaining interviews. This process helped facilitate examination of response differences between interviewees. Consistent with the guidelines of Spradley ${ }^{25}$ for conducting qualitative data analysis, as additional data were gathered, segments of the text were consistently reviewed for recurring themes. 


\title{
RESULTS
}

The results presented draw from content provided by the spectrum of PNIs who participated. Illustrative quotes are used to present examples of dominant themes. No differences were found based on the PNI background characteristics (i.e., neighborhood resident status, organizational affiliation, gender) or by neighborhood "risk" categorization. The results presented here are those that were mentioned most frequently.

\section{Intimate Partner Violence as a Neighborhood Issue}

Discord existed in perceptions of IPV as an issue in their neighborhoods.

Many participants associated IPV with only physical violence and either did not feel it was an issue in their neighborhood, or they felt only a few people were experiencing it. For example, as illustrated by one female participant, a neighborhood resident:

\begin{abstract}
No, it's more...every now and then you have a fight in the family but it's usually, it's not to the point where there's violence...(like real) VIOLENCE. Most of the time people don't tolerate that anymore. It's more fighting among the kids...it's more you know...street fights.
\end{abstract}

Estimates of incidence of IPV ranged from one couple in the year up to an estimated high of $40 \%$ of people with whom a person comes in contact within their neighborhood. Those who felt IPV was an important issue stated that although you might not personally see violence between couples, there are subtle signs. As illustrated by a local male pastor and local community program provider:

\begin{abstract}
No, because basically it's not talked about, only if you are moving around in the community watching people, looking and observing, you can see the hints of it, though it's not talked about it. Your eyes have to be open and your ears have to sometimes...listen for what's not said. If I see you and you're smiling today and the next day you're wearing dark shades and you won't take them off, and they fall off and I see a black eye...(nodding) you see how we hide it. The black community hides it and unless you are perceptive or paying attention. You'll never see it and say, 'Oh it's not an issue'... but it is.
\end{abstract}

\section{Neighborhood Factors Related to Intimate Partner Violence}

PNIs highlighted 2 neighborhood factors they perceived as major contributors to IPV. These included job availability and physical incivilities (living conditions).

\section{Job Availability}

Job opportunities in their immediate neighborhood were felt to be extremely limited. Lack of job availability and subsequent tensions arising from limited monetary resources reportedly amplify tensions between couples resulting in increased fighting. Female-headed households in which the female partner has a better paying job than her male partner also contributes to tensions and potential for violence. Several PNIs reported that many local employers tend to hire 
women from the neighborhood, not men. This status inconsistency created conflict within households, with one long-term male neighborhood resident stating:

...Because the woman becomes the bread winner. The man feels less. He may be working but he's not making as much as the woman and it causes him to be jealous and slap her a few times.

Another male past resident and program provider PNI similarly remarked that the lack of jobs for men in the community and presence of a working woman in the household could lead to frustration:

There's a frustration you know...of how does a person maintain the legitimacy... ahh...as the leader of the household with a lack of money... but the reality of it is...is that without a job and his own home...the guy is being out-competed by that check and the other things that come with it. Now...that's another great thing that enhances anger...guys actually beat women more when THEY have less...if they have a lot they give em more...but the girls have always come to almost understand that if a guy has less and lacks a job...she's gonna be the victim...

\section{Physical Incivilities}

Being surrounded by a dilapidated environment was felt to have a negative impact on people's perceptions of themselves, negative feelings may then develop into anger, and result in violence. As stated by another male pastor of a church in the study neighborhood and non-resident PNI:

Just imagine that you get up every day...and you look at an abandoned house across the street...and the trash...makes you feel depressed and desperate and men and women act differently...men get violent and sometimes women are the focus of that violence...or it spills into the street with youth and other innocent people in the area...

The presence of abandoned housing, trash and dilapidated buildings in the neighborhood offers another potential for promotion of IPV. The vacancy gives the opportunity for drug deals and use, groups to congregate, and opportunities for violence to ensue. Per one female and neighborhood resident PNI:

Those abandoned houses, you know, so something was always going on in those places. So, it's not as much now because a lot of the houses are boarded up...but the abandoned houses breed crime, breed violence, and things like that.

[Interviewer] Do you see that as having an impact on intimate partner violence?

Yes...yes...on all kinds of violence...because you could actually see females, even young females, 15 and 16 being jerked around by their friends or partners or whatever...so yeah, it had a definite effect [because] it was almost like that was expected...you know...people can get so far down or the situation can be so bad around you...you know...that people begin to think they're not worth anything! 


\section{Neighborhood Capacity to Intervene to Address Intimate Partner Violence}

Many PNIs felt there were few, if any, resources available in their neighborhoods or surrounding areas to individuals requiring assistance for IPV. This then required people to travel out of their immediate area to distant, often unfamiliar neighborhoods, to access resources. One participant described a health center that once existed to serve the needs of individuals, including those who are experiencing IPV, but was eventually closed down. After the closure of the facility, no other institution or services were set up in its place, leaving a void in the community members' health care system access. As stated by a female neighborhood resident PNI:

[Health and medical resources] ... need to be put back in the community so they [women who experience violence] can have somewhere to go to immediately ... now they have to travel out. I think that was really bad that they did that, I really do. I don't understand that. How can you give money for other stuff and you don't give money for health?

Many of the PNIs responded that those experiencing violence do not often discuss IPV. For the people choosing to share their experiences with IPV, they often disclosed to close friends or family members. For example, another female neighborhood resident PNI shared that:

The homes are so close...like netting...that you can't help but to know what's going on in the next person's house because the walls are thin. Anybody can tell you, you're gonna hear it. But they do, they show love, compassion for people, you know.

However, there were instances where people do confront the perpetrator and attempt to get them to stop their actions. As stated by one PNI:

We've got some of the guys that pull some of the guys away from the girls. They say...'Man, don't do that, don't do that.' They got the kid out here and all that, they say...man leave her alone. "And, it always happens the first of the month when the checks come out.

When asked how people in the neighborhood receive and share information regarding IPV and resources, PNIs stated most information was passed through discussions between community members, or "word of mouth." Others mentioned pamphlets and other publications being distributed occasionally in the neighborhoods.

\section{DISCUSSION}

This qualitative study gathered valuable insights regarding prominent neighborhood individual's perceptions of IPV, the role of neighborhood factors and neighborhood capacity to address it. Such information is critical to development of culturally sensitive intervention programs to address the complex problem of IPV.

Responses given during the interviews illustrate the differences in perceptions of IPV as an issue of concern in their communities. Some respondents felt it that IPV was not an issue or not present in their neighborhood, while others did feel it was 
present but not experienced by many people. These perceptions are notable and disturbing given that statistics from the state of Maryland during the same time period show that over 20,000 IPV crimes were reported by law enforcement agencies ${ }^{19}$ and that data from epidemiological studies of low-income urban women in Baltimore City found annual rates of IPV to be extremely high; one study found that over $60 \%$ of women reported any experience of abuse within the past 12 months. $^{26,27}$ However, failure to discuss and address IPV as a significant neighborhood issue of concern was common and expressed from PNIs, especially when the IPV remained behind closed doors, out of public view, or did not involve physical violence.

Several neighborhood factors, consistent to ecological theory, were felt by the PNIs to be related to IPV. Job availability and employment was thought to be an important influence on violence between couples. This qualitative perception is consistent with results from multi-level, quantitative, ecologically grounded studies showing that such economic factors are significantly associated with the prevalence of IPV. What is notable in our findings is the apparent acceptance of IPV as a vehicle for men residing in low-income neighborhoods to exercise their frustration, and power that they do not command in the job market. This finding is consistent with existing research which has identified stress as one perceived mechanism linking economic factors to the perpetration of IPV. ${ }^{10,12,13}$ On one hand, this finding is consistent with some theoretical understanding of IPV such as the status inconsistency theory which posits that men who perceive their status to be inconsistent with social norms may resort to violence as a means to compensate for their perceived lack of power. ${ }^{28-31}$ However, the PNIs' descriptions of their understanding of IPV suggest a belief that social stressors themselves may explain and potentially excuse male perpetration of IPV. The statement that a woman needs to "understand that if a guy has less and lacks a job...she's gonna be the victim," illustrates a certain acceptance of IPV as a normalized male response to unfortunate social stressors. In contrast, scholarly work exploring the etiology of IPV, such as feminist theory, emphasizes the contributions of gender inequality, male domination, and patriarchal gender roles to the occurrence of IPV.

In addition, the presence of abandoned and dilapidated housing and proliferation of trash were also felt to be related to IPV. Previous studies have identified that the relationship of such desperate neighborhood factors as contributing to increasing individual stress and stress within the intimate partner relationship which was seen as contributing to IPV. ${ }^{12,13}$ Appreciating these community perceptions and beliefs regarding IPV is crucial in developing programs and interventions to address IPV; a key component of such programming will be to address misconceptions and redefine acceptable norms.

Respondents highlighted as well a lack of IPV awareness and resources in their neighborhoods. Studies have shown that limited resources and opportunities may contribute to a women's inability, when ready, to engage in efforts to transition from their abusive relationship. ${ }^{32,33}$ Without resources such as health centers, shelters, and social service agencies, women dependent on their partners may not have any options for assistance if they do not have the support of an informal network of family and/or friends. These external resources are important as they offer alternatives to staying in abusive situations, skills for negotiating conflict that a woman's family, peer or extended social networks may not possess. In addition, this investigation provides valuable insight into why neighborhoods are able to provide protection or risk for IPV, which complement the findings demonstrated by previous multilevel studies. ${ }^{7}$ 
These qualitative findings can inform the development of hypotheses, which may be explored in greater detail and scope in larger population-based quantitative studies. As with all research though, there are a number of limitations worth noting. First, the generalizability of these findings is limited due to the small sample size and the focus on 4 urban neighborhoods. However, exploring local community perceptions is a critical first step towards understanding the contextual factors impacting complex health issues such as IPV. ${ }^{34}$ In addition, a potential limitation of this study involves the approach utilized to identify PNIs in that this study relied upon community individuals, rather than project staff, to identify local individuals involved in efforts to address and prevent neighborhood violence. The validity of this approach over others is dependent on the neighborhood engagement strategy, abilities and approach of the project staff, and individuals involved in the selection process. ${ }^{23}$ While this method of selection may have more face validity due to the involvement of local expertise, it also presents a unique limitation, specifically in that this approach depends on the abilities of the local expert and also contributed to limiting generalizability of findings. However, given the comprehensive approach to identifying community participants, these findings provide local formal and informal community leader's in-depth insights and perceptions of IPV, offering perspectives that are distinctive, unique, and too often untapped. The results of this study will be strengthened by additional qualitative and quantitative exploration of differing geographic neighborhood settings.

\section{CONCLUSION}

The issue of IPV is complex, as are the perceptions and capacity of neighborhoods to respond to it. Conditions of economic deprivation and limited resources greatly impact the ability of neighborhoods to identify, provide assistance, and offer support to IPV victims. Prominent neighborhood leaders were able to provide unique and valuable insight to the complex relationship of neighborhood influences and IPV. These findings suggest that urban health research and practitioners need to engage neighborhood leaders as partners to effectively raise awareness, and understanding of IPV as a problem that needs to be prevented and addressed.

\section{REFERENCES}

1. Osattin A, Short LM. Intimate partner violence and sexual assault: a guide to training materials and programs for health care providers. Atlanta, GA: Centers for Disease Control and Prevention, National Center for Injury Prevention and Control; 1998.

2. Saltzman LE, Fanslow JL, McMahon PM, Shelley GA. Intimate partner violence surveillance: uniform definitions and recommended data elements, Version 1.0. 1999; NCJ 186248.

3. Tjaden PG, Thoennes N. Extent, nature, and consequences of intimate partner violence: findings from the national violence against women survey. Rockville, MD: National Institute of Justice, US Dept of Justice; 2000. NCJ 181867.

4. Fox JA, Zawitz MW. Homicide trends in the United States web site. http://bjs.ojp.usdoj. gov/content/homicide/homtrnd.cfm. Accessed April 2, 2009.

5. Heise LL. Violence against women: an integrated, ecological framework. Violence Against Women. 1998; 4(3): 262-290. 
6. Dutton MA. Battered women's strategic response to violence: the role of context. In: Edleson JL, Eisikovits ZC, eds. Future interventions with battered women and their families. Thousand Oaks, CA: Sage Publications; 1996: 105-124.

7. O'Campo P, Gielen AC, Faden RR, Xue X, Kass N, Mei-Cheng Wang. Violence by male partners against women during the childbearing year: a contextual analysis. Am J Public Health. 1995; 85(8): 1092-1097.

8. Miles-Doan R. Violence between spouses and intimates: does neighborhood context matter? Soc Forces. 1998; 77(2): 623-646.

9. Cunradi CB, Caetano R, Clark C, Schafer J. Neighborhood poverty as a predictor of intimate partner violence among white, black, and hispanic couples in the United States: a multilevel analysis. Ann Epidemiol. 2000; 10(5): 297-308.

10. Burke JG, O'Campo P, Peak GL. Neighborhood influences and intimate partner violence: does geographic setting matter? J Urban Health. 2006; 83(2): 182-194.

11. Li Q, Kirby RS, Sigler RT, Hwang S, LaGory ME, Goldenberg RL. A multilevel analysis of individual, household, and neighborhood correlates of intimate partner violence among low-income pregnant women in Jefferson County, Alabama. Am J Public Health. 2010; 100(3): 531-539.

12. Burke JG, O'Campo P, Peak GL, Gielen AC, McDonnell KA, Trochim WMK. An Introduction to concept mapping as a participatory public health research method. Qual Health Res. 2005; 15(10): 1392-1410.

13. O’Campo P, Burke J, Peak GL, McDonnell KA, Gielen AC. Uncovering neighbourhood influences on intimate partner violence using concept mapping. J Epidemiol Community Health. 2005; 59(7): 603-608.

14. Jain S, Buka SL, Subramanian SV, Molnar BE. Neighborhood predictors of dating violence victimization and perpetration in young adulthood: a multilevel study. Am J Public Health. 2010; 100(9): 1737-1744.

15. Sampson RJ. Neighborhoods and violent crime: a multilevel study of collective efficacy. Science. 1997; 277: p918(7).

16. Sabol WJ, Coulton CJ, Korbin JE. Building community capacity for violence prevention. J Interpers Violence. 2004; 19(3): 322-340.

17. Emery CR, Jolley JM, Wu S. Desistance from intimate partner violence: the role of legal cynicism, collective efficacy, and social disorganization in chicago neighborhoods. Journal of Community Psychology. 2010. In press.

18. Yonas MA, O'Campo P, Burke JG, Gielen AC. Exploring local perceptions of and responses to urban youth violence. Health Promot Pract. 2010; 11(1): 62-70.

19. Yonas MA, O'Campo P, Burke JG, Gielen AC. Neighborhood-level factors and youth violence: giving voice to the perceptions of prominent neighborhood individuals. Health Educ Behav. 2007; 34(4): 669-685.

20. Iceland J, Steinmetz E. The effects of using census block groups instead of using census tracts when examining residential housing patterns website. http://www.census.gov/hhes/www/ housing/resseg/pdf/unit_of_analysis.pdf. Updated 2003. Accessed December 26, 2003.

21. Coulton CJ, Korbin JE, Su M. Measuring neighborhood context for young children in an urban area. Am J Community Psychol. 1996; 24(1): 5-32.

22. Maryland Department of Planning. web site. http://www.mdp.state.md.us/. Updated 2010. Accessed Nov 23, 2010.

23. Valente TW, Pumpuang P. Identifying opinion leaders to promote behavior change. Health Educ Behav. 2007; 34(6): 881-896.

24. Fraser D. QSR NVivo NUD*IST Vivo Reference Guide. 2000.

25. Spradley JP. The ethnographic interview. New York: Holt Rinehart and Winston; 1979.

26. Maryland Network Against Domestic Violence. Domestic Violence in Maryland Website. http://www.mnadv.org/ucr\%20stats.htm. Accessed Feb 20, 2004.

27. Gielen AC, McDonnell KA, O'Campo PJ. Intimate partner violence, HIV status, and sexual risk reduction. AIDS Behav. 2002; 6(2): 107-116. 
28. Dobash RE. Violence against wives: a case against the patriarchy. New York: Free Press; 1979.

29. Campbell JC. "If I can't have you, no one can": power and control in homicide of female partners. In: Radford J, Russell DEH, eds. Femicide: the politics of woman killing. New York: Twayne; 1992: 99-113.

30. Goode WJ. Force and violence in the family. J Marriage Fam. 1971; 33(4): 624-636. http://www.jstor.org/stable/349435.

31. Yick AG. Feminist theory and status inconsistency theory. Violence Against Women; 7(5): 545-562.

32. Miller BA, Downs WR. Violence against women. In: Goldman MB, Hatch MC, eds. Women and health. San Diego, Calif.: Academic; 2000: 529-539.

33. Sleutel MR. Women's experiences of abuse: a review of qualitative research. Issues Ment Health Nurs. 1998;19(6):525-539. http://search.ebscohost.com/login.aspx?direct=true $\& \mathrm{db}=\mathrm{aph} \& \mathrm{AN}=4041355 \&$ site $=$ ehost-live. $10.1080 / 016128498248827$.

34. Israel BA, Eng E, Schulz AJ, Parker EA. Methods in community-based participatory research for health/San Francisco. CA: Jossey-Bass; 2005. 